\title{
The Clinical Autonomic Research journal 2017 and onward
}

\author{
Horacio Kaufmann ${ }^{1,3} \cdot$ Jens Jordan ${ }^{2}$
}

Received: 24 December 2016/Accepted: 26 December 2016/Published online: 25 January 2017

(C) Springer-Verlag Berlin Heidelberg 2017

With each new year, many people make resolutions to achieve more and do better. For people, common resolutions are quitting smoking, taking up a sport, or losing some weight. As editors-in-chief of Clinical Autonomic Research, our resolutions for the year 2017 are to keep increasing the quality and relevance of our journal.

During 2016, the journal published important papers on timely and relevant topics such as supine hypertension in synucleinopathies [2], the relationship between orthostatic hypotension and cognitive performance [3], Takotsubo cardiomyopathy [5], autonomic dysfunction in autism spectrum disorder [4], or novel therapies for autonomic disorders [1]. Importantly, the average time to initial decision has dropped to 28 days, which, in our highly competitive environment, makes Clinical Autonomic Research an ideal journal for fast publication. The overall acceptance rate is at $42 \%$ (47\% in 2015). This is the direct result of our primary aim of enhancing the quality of our publication.

We want 2017 to be even better. To do so, we have made a number of improvements. First, we have strengthened our associate editors team with the addition of Dr. William Cheshire, Professor of Neurology at Mayo

Horacio Kaufmann

clinicalautonomicresearch@gmail.com

1 Department of Neurology, New York University School of Medicine, New York, USA

2 Institute of Aerospace Medicine, German Aerospace Center, Cologne, Germany

3 Clinical Autonomic Research Editorial Office, New York, USA
Clinic Florida. We also have a new managing editor, Dr. Alberto Palma, Assistant Professor of Neurology at New York University. We welcome both in their new roles with great expectations.

Second, we just launched the Facebook (www.facebook. com/ClinAutonRes) and Twitter (@ClinAutonRes) accounts of the journal to enhance the dissemination of our publication and to reach out further to the autonomic disorders community of researchers and patient advocacy groups.

Third, we have simplified the journal types of papers and updated the instructions for authors. Research articles, short communications, reviews, editorials, and letters to the editor are now the only articles types. Case reports and autonomic images are still welcome and encouraged, but they should be submitted as a letter to the editor.

This issue of Clinical Autonomic Research includes the list of the reviewers during 2016. We deeply acknowledge them all for their outstanding role in maintaining the scientific quality of the journal. Without their effort and dedication it would be impossible to keep Clinical Autonomic Research at the forefront of autonomic disorders.

We would like to wish the American Autonomic Society and the European Federation of Autonomic Society members, our readers, our authors, and our reviewers a successful and happy 2017.

Horacio Kaufmann MD

Jens Jordan MD PhD

Editors-in-Chief

\section{Compliance with Ethical Standards}

Conflict of interest The authors reports no relevant conflict of interests. 
Ethical approval This article does not contain any studies with human participants or animals performed by any of the authors.

Informed consent For this type of study formal consent is not required.

\section{References}

1. Elgebaly A, Abdelazeim B, Mattar O, Gadelkarim M, Salah R, Negida A (2016) Meta-analysis of the safety and efficacy of droxidopa for neurogenic orthostatic hypotension. Clin Auton Res Off J Clin Auton Res Soc 26:171-180

2. Fanciulli A, Gobel G, Ndayisaba JP, Granata R, Duerr S, Strano S, Colosimo C, Poewe W, Pontieri FE, Wenning GK (2016) Supine hypertension in Parkinson's disease and multiple system atrophy. Clin Auton Res Off J Clin Auton Res Soc 26:97-105

3. Feeney J, O'Leary N, Kenny RA (2016) Impaired orthostatic blood pressure recovery and cognitive performance at two-year follow up in older adults: The Irish Longitudinal Study on Ageing. Clin Auton Res Off J Clin Auton Res Soc 26:127-133

4. Harder R, Malow BA, Goodpaster RL, Iqbal F, Halbower A, Goldman SE, Fawkes DB, Wang L, Shi Y, Baudenbacher F, Diedrich A (2016) Heart rate variability during sleep in children with autism spectrum disorder. Clin Auton Res Off J Clin Auton Res Soc 26:423-432

5. Madias JE (2016) Atypical global Takotsubo syndrome in a patient with acute disseminated encephalomyelitis. Clin Auton Res Off J Clin Auton Res Soc 26:161 